\title{
Loss aversion in a consumption-savings model
}

\author{
David Bowman*, Deborah Minehart, Matthew Rabin \\ Board of Governors of the Federal Reserve System, Division of International Finance, \\ Mail Stop 24, Washington DC 20551, USA
}

Received 25 October 1997; accepted 28 September 1998

\begin{abstract}
We propose a model of consumption and saving based on Kahneman and Tversky's Prospect Theory that implies a fundamental asymmetry in consumption behavior inconsistent with other models of consumption. When there is sufficient income uncertainty, a person resists lowering consumption in response to bad news about future income. This resistance is greater than the resistance to increasing consumption in response to good news. We present empirical evidence from five countries that confirms this behavior. (C) 1999 Elsevier Science B.V. All rights reserved.
\end{abstract}

JEL classification: A12; B49; C91; D11; D81; E21

Keywords: Consumption; Habit formation; Loss aversion; Reference points; Risk aversion; Savings

\section{Introduction}

Psychological evidence reviewed in Kahneman et al. (1991) and Camerer (1995) indicates that a person's well-being depends not only on his current consumption of goods, but also on how his current consumption compares to his past consumption. Kahneman and Tversky (1979), Tversky and Kahneman $(1991,1992)$ suggest that a fundamental asymmetry in the evaluation of increases and decreases in consumption underlies many instances of reference dependence: People care much more about losses relative to their reference point than about gains. Moreover, while people are risk-averse in gains, they are risk-loving in losses. We refer to these combined characteristics as loss aversion.

In this paper, we develop a two-period consumption/saving model where a loss-averse consumer faces uncertainty over his second-period income. We assume that in each period the agent's utility depends both upon his level of consumption and a comparison of this level to a reference point that depends on past consumption.

* Corresponding author. 
Our main conclusion is that there is a fundamental asymmetry in the response of consumption to anticipated changes in income. When there is sufficient income uncertainty, a person resists consuming below his reference point in the first period even when his expected average per-period income is below his reference point, whereas upward revisions are more likely to immediately affect consumption. Our model thus conforms with general intuition, dating at least back to Duesenberry (1952), that people resist decreasing their standard of living in response to bad news about income.

An important empirical implication is that downward revisions in expected future income growth tend to have a greater impact on expected consumption growth than upward revisions. That is, when a person receives good news regarding future income prospects, he may immediately adjust current consumption upward, thereby reducing or even eliminating the possibility of a further increase in future consumption. In contrast, learning today of a negative shock to income in some future state(s) of the world may have no effect on current consumption, implying that future consumption will decrease significantly tomorrow if the shock is realized. We provide empirical evidence from five countries supporting this implication. This extends recent empirical research by Shea (1995a, b) that also provides evidence of asymmetric behavior consistent with this implication of our model. These results are inconsistent with both the Permanent Income Hypothesis and with alternative explanations of other apparent violations of the Permanent Income Hypothesis, such as liquidity constraints or Campbell and Mankiw's (1989) rule-of-thumb behavior.

Section 2 presents Kahneman and Tversky's (1979) original formulation of loss aversion, our extensions, and a simple proposition comparing loss aversion to the standard economic model of risk aversion. Section 3 presents our consumption/saving model and its implications. Empirical evidence is presented in Section 4. Section 5 considers possible extensions and discusses the empirical implications of our results.

\section{Loss aversion and changing reference points}

We assume that a person's per-period utility function can be represented by a function $U(r, c)$, where $c$ is his consumption level and $r$ is his reference level of consumption. Kahneman and Tversky's theory posits a 'gain-loss utility function' measuring how people are affected by movements in consumption about a fixed reference point. We assume that this gain-loss utility function is independent of the reference point itself, depending only on the difference between consumption and the reference point, $c-r$. The consumer's overall utility can then be written as:

$$
U(r, c) \equiv w(r)+v(c-r),
$$

where $v(\cdot)$ is the gain-loss utility function, and $w(\cdot)$ is the 'reference utility.' The function $w(\cdot)$ represents any residual way in which the consumer's utility depends on movements in the reference point, holding the difference between consumption and the reference point, $c-r$, fixed. We assume that $U(\cdot, \cdot)$ is defined for all non-negative values of $r$ and $c$. We normalize $v(\cdot)$ to be equal to zero if $c=r$, so that $v(0)=0$ and $U(r, r)=w(r)$. For convenience, we shall also assume that both components of the utility function are continuous, have a bounded slope, and, except when $c=r$, are twice differentiable. 


\subsection{Loss aversion}

We begin with the assumptions on the utility function incorporated into Kahneman and Tversky's Prospect Theory.

Assumptions A1-A3:

A1. $v(x)$ is strictly increasing in $x$.

A2. If $y>x>0$, then $v(y)+v(-y)<v(x)+v(-x)$.

A3. $v(x)$ is strictly concave for $x>0$ and strictly convex for $x<0$.

Assumption A1 implies that $U(r, c)$ is increasing in $c$, which simply says that 'more is better.' Assumption A2 implies that the marginal utility of a loss is strictly greater than the marginal utility of a comparable gain - a property shared with standard models of concave utility.

A3 represents an assumption of diminishing marginal sensitivity to changes in consumption: the marginal utility of a further gain in consumption decreases as the gain grows larger, and similarly the marginal disutility of a further loss in consumption decreases as the loss grows larger. ${ }^{1}$ This implies that people are risk-averse in situations involving a sure gain, but it also implies that people are risk-loving in situations involving a sure loss.

Psychological evidence indicates that people have a relative distaste for losses even when comparing very small losses to very small gains, and the utility functions estimated by Kahneman and Tversky incorporate this feature. We formalize this idea in Assumption A4:

Assumption A4: If $x>0$, then $\lim _{x \rightarrow 0} \frac{v^{\prime}(-x)}{v^{\prime}(x)} \equiv L>1$.

Pratt (1964) and Arrow (1974) demonstrated that standard utility theory predicts that people are close to risk-neutral for small bets, implying the acceptance of any slightlybetter-than-fair bet if it is small enough. Due to Assumption A4, loss aversion instead predicts the rejection of any slightly-better-than-fair bet if it is small enough. ${ }^{2}$ Formally, consider a bet as a distribution $f$ over gains and losses, and say that it is scaled by $k>0$ when all values of $f$ are multiplied by $k$. Then standard theory predicts that for every better-than-fair bet $f$, there exists $\epsilon>0$ such that for all $k<\epsilon$, a person will accept the bet $f$ scaled by $k$. In contrast, Assumptions A1-A4 imply: ${ }^{3}$

Proposition 1: Let $f$ be any better-than-fair bet with a lower bound on losses and a positive probability of a loss, let $g$ be any fair bet with a lower bound on losses, and let $h(p) \equiv p f+(1-p) g$ for $p \in(0,1]$. If Al-A4 hold then there exists an $\epsilon>0$ and $p^{*}>0$ such that for all $k<\epsilon$ and $p<p^{*}$, a person will reject $h(p)$ when scaled by $k$.

\footnotetext{
${ }^{1}$ The idea that risk attitudes are based upon deviations in consumption from a reference point goes back at least to Markowitz (1952).

${ }^{2}$ Recent papers such as Segal and Spivak (1990) also modify utility theory to obtain this type of 'first-order risk aversion' (where slightly-better-than-fair bets are turned down no matter how small). In contrast to the theory presented here, this literature obtains first-order risk aversion by relaxing the assumption of expectedutility maximization.

${ }^{3}$ All proofs are in the Appendix A.
} 
In part of what follows we will find it convenient to impose a further condition on the gain-loss utility function. Kahneman and Tversky's experimental evidence indicates that the ratio of loss aversion - the marginal utility of losses divided by the marginal utility of gains - is generally between 2 and 2.5. That is, a loss of one unit is more than twice as unpleasant as a gain of one unit is pleasant. Assumption B1 makes this property global: ${ }^{4}$

Assumption B1: For all $x \geq 0, y<0, v^{\prime}(y)>2 v^{\prime}(x)$.

\subsection{Changing reference points}

In an intertemporal setting, future reference points may be affected by current choices. Recognizing this, individuals may incorporate reference point effects into their consumption decisions. For instance, a consumer may be wary of developing a luxurious lifestyle because he knows that doing so will make him less happy if he later becomes impoverished. We must therefore make assumptions about how a person's welfare depends on his reference point.

We make a standard assumption in models of habit formation: An equal increase in both the level of consumption and the reference level of consumption does not decrease utility, and may increase it. ${ }^{5}$ In addition, we assume that the marginal utility of an equal increase in consumption and the reference level is non-increasing. These conditions are represented in Assumption A5:

Assumption A5: $U_{r}(r, c)+U_{c}(r, c) \geq 0 . U_{r r}(r, c)+2 U_{r c}(r, c)+U_{c c}(r, c) \leq 0$.

Assumption A5 implies that $w(\cdot)$ is non-decreasing and weakly concave everywhere. As it is equivalent to $U(r, r), w(r)$ can be interpreted as a sort of 'reference-adjusted' utility function, representing a consumer's utility from consuming at level $r$ when he is accustomed to that level.

The next assumption also accords with most models of habit formation:

Assumption B2: $U(r, c)$ is decreasing in $r$.

Assumption B2 says that a person derives more satisfaction from a fixed consumption level the lower his reference point. It is equivalent to the condition that $w^{\prime}(x)<v^{\prime}(y)$ for all $y$ and all $x \geq 0$.

While Assumption B2 will perhaps strike many readers as natural, it is not the only assumption that might realistically be made in this context. It is at odds with models such

\footnotetext{
4 Tversky and Kahneman's (1992) estimate of $v(\cdot)$ implies that the marginal disutility of a loss is greater than the marginal utility of a gain whenever the loss is less than 860 times the size of the gain. Assumption B1 is stronger than this, implying that the marginal disutility of any loss (including an infinite loss) is greater than the marginal utility of even a small gain. As we do not believe our results to be relevant in the case of very large income losses, we believe that Assumption B1 does relatively little damage.

${ }^{5}$ See Georgescu-Roegen (1954), Ryder and Heal (1973), Sundaresan (1989), and Constantinides (1990) for literature on habit formation. Dynan (1993b) estimates a model of the form $U(r, c)=(c-\gamma r)^{\rho}$, where the reference point, $r$, is last period's level of consumption and finds a value of $\gamma$ that is strictly less than 1; since utility can be rewritten as $((c-r)+(1-\gamma) r)^{\rho}$, this estimate implies that an equal increase in both the level of consumption and the reference point will increase utility.
} 
as Boyer (1983) that assume consumption is a type of durable good, where higher past consumption raises the pleasure of current consumption. For certain goods it seems reasonable to assume that people derive more satisfaction from a given level of consumption once they have developed a taste for it through past consumption. Examples might include one's enjoyment of certain types of music or food (or levels of exercise). On the other hand, someone who is currently deprived of a given level of consumption is likely to feel a greater sense of loss if he has been accustomed to it. The following alternative to $\mathrm{B} 2$ represents preferences of this type:

Assumption $C: U(r, c)$ is decreasing in $r$ when $r>\mathrm{c}$, and increasing in $r$ when $r<c$.

Assumption $\mathrm{C}$ says that fixing a consumption level, $c$, the nearer $r$ is to $c$ the greater the utility from consuming $c$ will be. We call this assumption acclimation. It is equivalent to the conditions that $w^{\prime}(x)<v^{\prime}(y)$ for all $x \geq 0, y \geq 0$ and that $w^{\prime}(x)<v^{\prime}(y)$ for all $x \geq 0$, $y \leq 0$.

Since the literature on prospect theory has not focused on the process of reference point formation, we do not have experimental evidence describing how utility changes as the reference point changes. Accordingly, we will assume that A1-A5 hold and hat in addition either $\mathrm{B} 1-\mathrm{B} 2$ or $\mathrm{C}$ holds. Except where noted, all of our results hold in either case. An assumption such as B1-B2 or C is necessary to guarantee some basic regularity of intertemporal behavior. In conjunction with A1-A5, either B1-B2 or $\mathrm{C}$ guarantees that a person will not exhibit 'starve-binge' behavior - purposely consuming below his reference point now solely to consume above his reference point in the future.

\section{A two-period model of consumption/saving}

We now consider a simple model of consumption and saving decisions. We assume that two periods remain in a consumer's life, and that any uncertainty in his income is resolved in the second period. There are no liquidity constraints that prevent him from consuming any guaranteed second-period income in the first period, but consumption is not allowed to be negative in either period, so that he cannot borrow against an uncertain future income (which would risk-default). For simplicity, we assume no discounting and that savings earn no interest. Let $r_{t}$ be the reference level in period $t, Y_{t}$ be income in period $t$, and $c_{t}$ be consumption in period $t$. The consumer's problem is to maximize expected lifetime utility, given by

$$
U\left(r_{1}, c_{1} ; r_{2}, c_{2}\right) \equiv w\left(r_{1}\right)+v\left(c_{1}-r_{1}\right)+E\left\{w\left(r_{2}\right)+v\left(c_{2}-r_{2}\right)\right\},
$$

subject to the constraint that

$$
c_{1}+c_{2}=Y_{1}+Y_{2}
$$

This maximization problem is clearly influenced by the way reference points are formed. We model reference-point formation in a manner consistent with recent literature on habit formation in consumption. We take the first-period reference point, $r_{1}$, as exogenously determined and the second-period reference point, $r_{2}$, as determined in part 
by $r_{1}$ and in part by first-period consumption, $c_{1}$ :

$$
r_{2} \equiv(1-\alpha) r_{1}+\alpha c_{1},
$$

where $\alpha \in[0,1]$ represents the speed at which the reference point changes in response to recent consumption. If $\alpha=0$, then first-period consumption has no effect on the consumer's second-period reference level, so that utility is time-separable; if $\alpha=1$, then the second-period reference level adjusts fully to first-period consumption. ${ }^{6}$

\subsection{Consumption behavior when income is certain}

We begin by examining the consumer's behavior when income is certain. We denote by $c_{1}(Y)$ and $c_{2}(Y)$ the consumer's choice of first- and second-period consumption if faced with a sure average per-period income of $Y \equiv\left(Y_{1}+Y_{2}\right) / 2$. We will refer to Assumptions A1-A5 collectively as A and B1-B2 as B when stating Theorems or Propositions. Our results are summarized by Theorem 1 :

Theorem 1: If $A$ and either $B$ or $C$ hold, then (1) $c_{1}(Y)$ and $c_{2}(Y)$ are continuous and non-decreasing, with $c_{1}(Y)=c_{2}(Y)=r_{1}$ when $Y=r_{1}$ and $\left(c_{1}(Y)-r_{1}\right)\left(c_{2}(Y)-r_{2}\right) \geq 0$. (2) If $Y \leq r_{1}$ then $\left(c_{1}(Y)-r_{1}\right)\left(c_{2}(Y)-r_{2}\right)=0$ whenever the constraint $c_{t} \geq 0$ is nonbinding. If in addition $\alpha>0$, then $c_{2}(Y)=r_{2}$.

The first part of Theorem 1 implies that both first- and second-period consumption are normal goods and that a person will consume below his reference level only if his lifetime income cannot support continued consumption at that level. It also says that he will not consume above his reference point in one of the two periods if that choice will force him to consume below his reference point in the other period.

The second part of Theorem 1 says that under loss aversion a person will concentrate all of his losses in one period. While consumption is smoothed over time under the Permanent Income Hypothesis, in our framework risk-loving attitudes towards losses cause consumers to lump declines in consumption together. If utility is time-separable $(\alpha=0)$ the consumer is equally well off concentrating his losses in either period. With habit formation $(\alpha>0)$ the consumer strictly prefers to concentrate losses in the first period because doing so lowers his second period reference level.

The results of Theorem 1 can be strengthened when preferences exhibit acclimation:

Proposition 2: If preferences satisfy $A$ and $C$, then $c_{1}(Y)$ and $c_{2}(Y)$ are strictly increasing in $Y$ whenever the constraint $c_{t} \geq 0$ is non-binding and $\alpha>0$.

A necessary condition for the conclusion of Proposition 2 to hold is given by:

Proposition 3: If preferences satisfy $A$, then Theorem 1 holds and $c_{1}(Y)$ and $c_{2}(Y)$ are strictly increasing when the constraint $c_{t} \geq 0$ is non-binding for all $Y, r_{1}$, and $\alpha>0$ only if $U(c, c)>U(r, c)$ for all $c$ and $r \neq c$.

\footnotetext{
${ }^{6}$ Our model is one of fully forward-looking behavior; however, a consumer who ignores the effects of consumption choices on future reference points will act as if $\alpha$ is low in our model, and so a low value for $\alpha$ could be reinterpreted as a form of myopia. Due to the asymmetry found in our model, this form of myopia would differ from the type displayed by Campbell and Mankiw's (1989) rule-of-thumb consumers, who set consumption equal to current income.
} 
Formally, Proposition 3 says that the less intuitive aspect of acclimation - that a person with high consumption is happier when acclimated to that standard of living than when accustomed to being poor - is necessary to insure that consumption choices strictly increase in lifetime income. ${ }^{7}$ As intuition, consider the choice between spreading an income increase across consumption in both periods or consuming it all in the second period. Under the first choice, $r_{2}$ adjusts upwards, bringing it closer to $c_{2}$ than it would be under the second choice. Since this is desirable under acclimation, the consumer prefers to spread his income increase across both periods.

\subsection{Consumption behavior when income is uncertain}

While it is possible to form a fairly simple and complete characterization of consumption behavior under certainty when preferences exhibit loss aversion, there is a wider range of possible behavior under uncertainty. ${ }^{8}$ Rather than focus on a specific random distribution for second-period income or a specific functional form for utility, we focus on what we take to be standard behavior under a wide variety of income distributions and functional forms and on those theorems that we have been able to prove for any set of preferences meeting our assumptions.

Our most important finding is that when there is enough uncertainty, people resist lowering consumption in response to news that they will probably not be able to maintain their standards of living. Theorem 2 states that as long as future per-period income exceeds the current reference level with at least probability $\alpha / 1+\alpha$ under Condition $\mathrm{C}$ or $2 \alpha / 1+\alpha$ under Conditions B1-B2, a person will consume at or above his reference level in the first period no matter how low his expected lifetime income is (as long as he does not risk default):

Theorem 2: If assumptions $A$ and $C$ hold and $P\left[Y \geq r_{1}\right] \geq \alpha /(1+\alpha)$, or if Assumptions $A$ and $B$ hold and $P\left[Y \geq r_{1}\right] \geq 2 \alpha /(1+\alpha)$, then $c_{1} \geq r_{1}$ whenever $P\left[Y \geq 0.5 r_{1}\right]=1$.

This result depends on the two aspects of loss aversion that are most non-standard to economists: dependence on reference points and risk-loving preferences in losses. As in our analysis of consumption under certainty, risk-loving behavior leads a person to concentrate losses. However, while habit formation always leads the consumer to concentrate losses in the first period when income is certain, under uncertainty there is a

\footnotetext{
${ }^{7}$ The more intuitive aspect of acclimation - that when a person's reference level is above his current consumption, he is happier the lower is his reference point - is slightly stronger than necessary. Proposition 3 only requires that the consumer prefer $r=c$ to $r>c$, not that utility continuously decrease in $r$ for $r>c$. To understand the difference, observe that the utility function $U(r, c)$ is concave in the region where $c>r$. This fact can be used to show that $U(c, c)>U(r, c)$ for all $c>r$ if and only if $w^{\prime}(x)>v^{\prime}(y)$ for all $x \geq 0$ and $y \geq 0$. In contrast, $U(r, c)$ need be neither concave nor convex in the region where $c<r$. As a result, while $w^{\prime}(x)<v^{\prime}(y)$ for all $x \geq 0, y \leq 0$ is sufficient to imply $U(c, c)>U(r, c)$ for all $c<r$, it is stronger than necessary since examples can be constructed in which $w^{\prime}(x)>v^{\prime}(y)$ for some $x \geq 0, y \leq 0$ but $U(c, c)>U(r, c)$ for all positive $c<r$.

${ }^{8}$ For example, in the conventional concave-utility framework, the monotonicity obtained in Theorem 1 extends to cases of uncertainty: If lottery $g$ first-order stochastically dominates lottery $h$, then first-period consumption will be at least as high given income stream $g$ than given income stream $h$. We have constructed examples in which this feature does not hold in our model. However, these examples depend on a high degree of convexity in losses and are, therefore, in a loose sense unlikely.
} 
strong incentive to postpone these losses, since there is some chance that future income will be high enough to avoid taking any loss at all. For low values of $\alpha-$ a slowly changing reference point - this second effect predominates. If a person's reference point is completely unaffected by current changes in consumption $(\alpha=0)$, then Theorem 2 implies that he will never consume below his reference level in the first period so long as his income is high enough to satisfy the constraint against default.

Theorem 2 implies an asymmetry in consumer behavior under loss aversion. Although first-period consumption never lies below the reference level when the probability of gain exceeds the bounds given by Theorem 2, consumption may lie above the reference level even when the probability fails to meet these bounds. ${ }^{9}$

Proposition 4: The converse of Theorem 2 does not hold. That is, neither Conditions A, $C$, and $P\left[Y \geq r_{1}\right]<\alpha /(1+\alpha)$ nor Conditions $A, B$, and $P\left[Y \geq r_{1}\right]<2 \alpha /(1+\alpha)$ imply that $c_{1} \leq r_{1}$.

Fig. 1(a), which graphs the expected growth rate of consumption as a function of the expected growth rate of income, demonstrates the type of asymmetric consumption behavior that can be generated by our model. We consider power utility over gains and losses and, for simplicity, a binomial distribution of second-period income:

$$
\begin{gathered}
U(c, r)=\left\{\begin{array}{ll}
w r+\frac{1}{1-\gamma}\left(b_{g}+c-r\right)^{1-\gamma} & \text { if } c>r \\
w r-\frac{1}{1-\lambda}\left(b_{l}+r-c\right)^{1-\lambda} & \text { if } c \leq r
\end{array}\right\} \\
Y_{1}=r_{1}, \operatorname{Prob}\left(Y_{2}=Y_{h}\right)=\operatorname{Prob}\left(Y_{2}=Y_{l}\right)=1 / 2
\end{gathered}
$$

The solution is illustrated for $\alpha=0$ and $\alpha=1$ as the expected growth rate of income is varied. ${ }^{10}$ In this example, the consumer postpones reducing consumption whenever the news is bad. This highlights the fact that Theorem 2 provides only necessary, not sufficient, conditions since first-period consumption remains at the reference level for $\alpha=1$ even when there is zero probability of a gain. As a result, a 1 percent decline in expected income growth leads to a 1 percent decline in expected consumption growth. However, a 1 percent increase in expected income growth leads to less than a 1 percent increase in expected consumption growth, as the agent reacts to sufficiently good news by raising first-period consumption.

These results are contrasted with Fig. 1(b), which presents the results of the same experiment (with the same parameters) when utility everywhere is concave $v(c-r)=$

\footnotetext{
${ }^{9}$ It is important to note that Proposition 4 does not imply that consumption will be above the reference level whenever the probability of a gain exceeds the bounds of Theorem 2 . Whether consumption will lie above the reference level depends upon several factors. It is more likely to occur the higher the level of risk aversion over gains, the lower the level of risk-seeking over losses, or the smaller the ratio of loss aversion. Expected increases in income that are not skewed towards large, low probability positive outcomes also make it more likely because under loss aversion the consumer is more concerned about reducing the probability of a loss than about reducing its size.

${ }^{10}$ To generate Fig. $1, Y_{1}$ and $r_{1}$ were normalized to 1 and the shock to second-period income was set so that its standard deviation was $10 \%$ of first-period income. The other parameters, $b_{g}=1 ; b_{l}=1.1 ; \gamma=1.25 ; \lambda=0.05$; and $\omega=0.9$, were chosen to satisfy A1-A5 and $\mathrm{C}$ over the relevant range of consumption choices. Constants should be added to the function $v()$ to satisfy our normalization $v(0)=0$; they have been omitted from the text.
} 

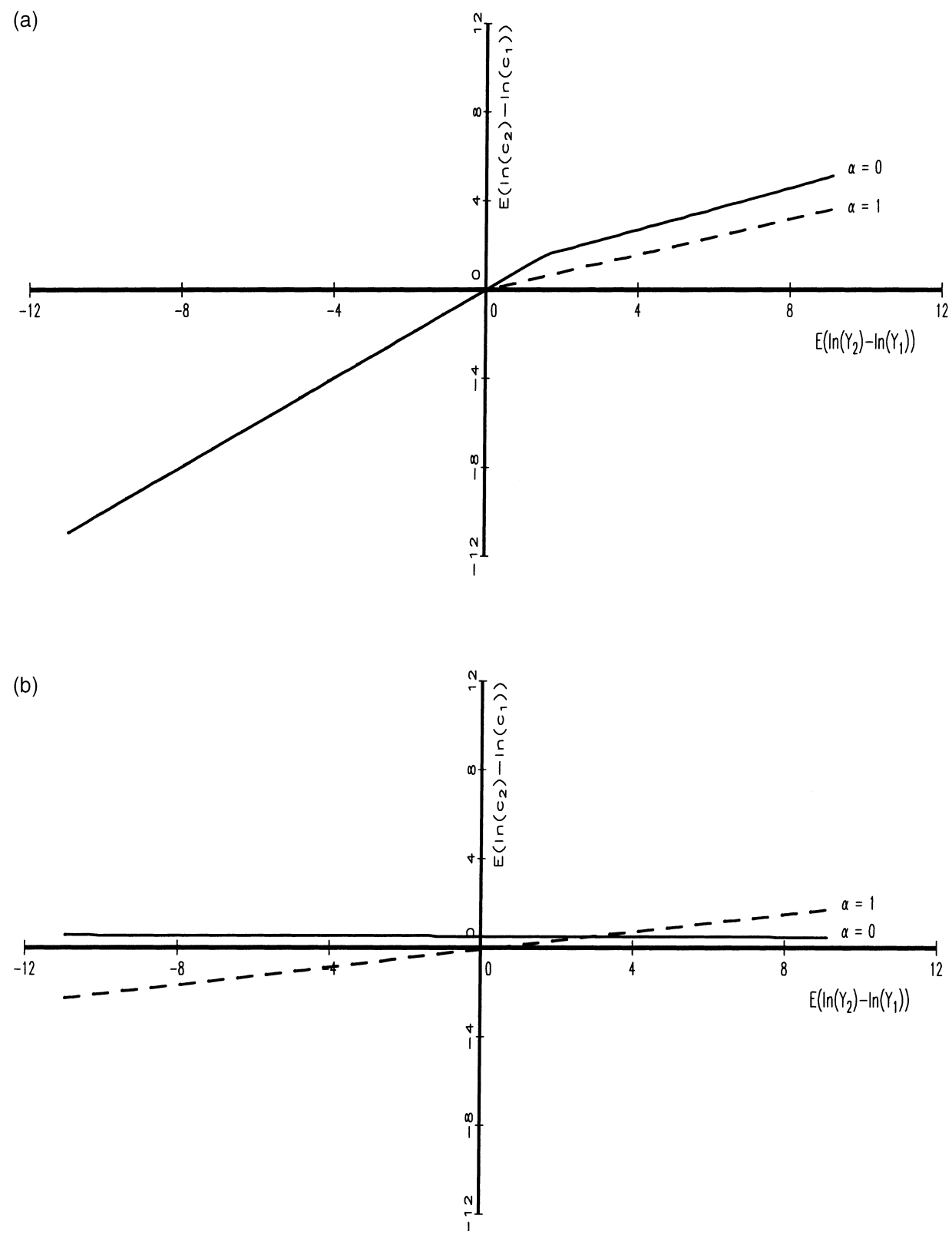

Fig. 1. (a) Consumption behavior with loss aversion (scales in \%); (b) Consumption behaviour without loss aversion (scales in \%).

$1 /(1-\gamma)\left(b_{g}+c-r\right)^{1-\gamma}$ for all values of $c$. For $\alpha=0$ utility is time-separable, in this case, as in standard log-linear representations of the Permanent Income Hypothesis, $E(\Delta$ $\left.\ln c_{t}\right) \approx \mu$, where $\mu$ is a constant that depends on income uncertainty, interest rates, and 
the consumer's discount rate. ${ }^{11}$ Under the Permanent Income Hypothesis, the expected growth rate of consumption is unrelated to the expected growth rate of income, and this is what occurs when $\alpha=0$. When $\alpha=1$ we have a concave-utility model of habit formation, where the expected growth rate of consumption is related to the expected growth rate of income, as agents only slowly adjust consumption to changing income. However, unlike the results of our model, the relationship between expected consumption growth and expected income growth is symmetric.

We close this section with a brief comment on how changes in income uncertainty affect consumption in our model. Leland (1968) shows that in a conventional, time-separable, concave-utility model, agents increase saving in response to increased income uncertainty when the third derivative of the utility function is positive. ${ }^{12}$ In our model, an increase in uncertainty can either increase or decrease consumption, as shown in Proposition 5:

Proposition 5: Let $c_{1}(Y, k)$ be the consumer's first-period consumption when faced with probabilistic total income $((1-k) Y,(1+k) Y)$, where $k \in[0,1]$. (i) If $A$ holds and $\alpha>0$, then there exists $Y^{*}<r_{1}$ such that for all $Y \in\left(Y^{*}, r_{1}\right)$ and $k$ satisfying $(1-k) Y>0.5 r_{1}$, $c_{1}(Y, k)>c_{1}(Y, 0)$. (ii) If $A$ and $C$ hold, then there exists $k^{*}>0$ and $Y^{*}>r_{1}$ such that for all $Y \in\left(r_{1}, Y^{*}\right)$ and all $k<k^{*}, c_{1}(Y, 0)>c_{1}(Y, k)$.

When expected income is slightly below the reference level an increase in the probability that a consumer will be able to consume above his reference level in each period leads him to decrease savings. Part (i) of Proposition 5 illustrates this idea. Part (ii), on the other hand, suggests that if expected per-period income is slightly above the reference level an increase in uncertainty is likely to increase savings. While part (ii) of Proposition 5 need not generalize to non-binary symmetric distributions, the intuition behind its proof is that when expected average per-period income exceeds the reference point, an increase in uncertainty that raises the odds that the consumer will not be able to maintain his current consumption level will increase his saving. ${ }^{13}$ Roughly, this holds whenever the effect of increasing the odds of being forced to consume below one's reference level is not outweighed by behavioral changes relating to third-derivative features of the various components of the utility function.

\section{Empirical validation}

Our empirical analysis tests our prediction of an asymmetry in behavior in response to positive and negative shocks to permanent income. As is well known, log-linear versions

\footnotetext{
${ }^{11}$ When agents have power utility and second-period consumption is log-normally distributed, this equation will be exact. If these conditions do not hold, then it can be derived as a second-order Taylor approximation (see Campbell and Mankiw, 1989 and the references therein).

12 See also Kimball (1990a, b), Zeldes (1989), and Caballero (1990). The empirical evidence in favor of this type of precautionary saving appears to be weak. Dynan (1993a) finds at best a very small precautionary saving motive among households in the Consumer Expenditure Survey and is unable to reject the hypothesis that no precautionary saving takes place.

13 Theorems 1 and 2 make clear, however, that part (i) generalizes to any symmetric distribution. The fact that part (i) of Proposition 5 holds more generally than part (ii) seems to be related to the asymmetry in Theorem 2 and Proposition 4.
} 
of the type of intertemporal optimization problem first tested by Hall (1978) imply a version of the Permanent Income Hypothesis in which expected consumption growth is independent of movements in expected income growth. In our model, loss aversion implies that consumers resist lowering current consumption below its reference level in response to a negative shock to future income. As discussed in previous sections, this can yield an asymmetry in which expected consumption growth reacts more to declines in expected income growth than to increases.

This asymmetry in behavior is at odds not only with the predictions of the Permanent Income Hypothesis, but also with other alternatives to the Permanent Income Hypothesis proposed in the literature, including liquidity constraints, Campbell and Mankiw's (1989) rule-of-thumb behavior, and with other recent literature on habit formation. Campbell and Mankiw's rule-of-thumb behavior does not produce asymmetric consumption responses. As liquidity constraints reflect an inability to borrow against future income rather than an inability to save, they should imply a high consumption response to previously expected income growth, rather than to previously expected income declines. Finally, as discussed in the previous section, concave models of habit formation cannot explain evidence that consumption reacts more slowly to news of a future decline in income than it does to a future rise in income.

Evidence of the existence of this type of asymmetric consumption behavior has previously been found in U.S. data by Shea (1995a, b). Using information on union contracts to construct a measure of expected wage growth for each household in his sample, Shea (1995a) finds that when wages change consumption responds more to predictable declines in wages than to predictable increases. While Hall's test of the Permanent Income Hypothesis is rejected for predictable wage declines, it cannot be rejected for predictable wage increases. Using the framework developed in Campbell and Mankiw (1989, 1990, 1991), Shea (1995b) tests for and finds the same asymmetry in aggregate U.S. data. Here we extend Shea (1995b) and Campbell and Mankiw (1991) by testing for the same asymmetry using cross-country data.

Campbell and Mankiw assume that a fraction $(1-\lambda)$ of consumers follow the Permanent Income Hypothesis and another fraction $\lambda$, called 'rule-of-thumb' consumers, simply consume some constant fraction of their current income. They estimate $\lambda$ to be about 0.5 for the United States, indicating that about 50 percent of U.S. consumption cannot be explained by the Permanent Income Hypothesis. Campbell and Mankiw (1991) report qualitatively similar findings using cross-country data.

Shea (1995b) extends this methodology in the following manner. An estimate of $\lambda$ can be formed by the regression:

$$
\Delta \ln c_{t}=\mu+\lambda \Delta \ln \hat{y}_{t}+\epsilon_{t}
$$

where $\Delta \ln c_{t}$ is consumption growth between time $t$ and $t_{1}$, and $\Delta \ln \hat{y}_{t}$ is expected income growth between $t$ and $t-1$ - formed by projecting income growth against a set of variables in the consumer's information set at time $t-1$. Shea instead ran the regression:

$$
\Delta \ln c_{t}=\mu+\lambda_{1}\left(\mathrm{POS}_{t}\right) \Delta \ln \hat{y}_{t}+\lambda_{2}\left(\mathrm{NEG}_{t}\right) \Delta \ln \hat{y}_{t}+\epsilon_{t},
$$

where POS is a dummy variable for periods in which expected income growth is positive, and NEG is a dummy variable for periods in which expected income growth is negative. 
Table 1

Estimates of the model

\begin{tabular}{llrrr}
\hline Country & Sample period & \multicolumn{1}{c}{$\bar{R}_{c}^{2}$} & \multicolumn{1}{c}{$\bar{R}_{y}^{2}$} & $\lambda$ \\
\hline Canada & $1972: 4-94: 1$ & 0.271 & 0.161 & $0.497(5.31)$ \\
France & $1971: 2-93: 2$ & 0.117 & 0.065 & $0.293(1.97)$ \\
West Germany & $1961: 2-90: 2$ & 0.005 & 0.048 & $0.592(2.48)$ \\
Japan & $1971: 2-93: 1$ & -0.007 & -0.037 & $-0.269(-0.89)$ \\
United Kingdom & $1956: 2-93: 3$ & 0.109 & 0.012 & $0.423(2.63)$ \\
\hline
\end{tabular}

He finds a much higher response to previously predicted income declines than to previously predicted income growth. This corresponds to the asymmetry predicted by our model: when consumers do not immediately respond to predicted future declines in income, they must respond by more at the time income actually declines.

Our dataset consists of quarterly real per-capita consumption and personal disposable income for five countries: Canada, France, West Germany, Japan, and the United Kingdom. This set of countries is the same as that studied in Campbell and Mankiw (1991) with three exceptions: we include estimates for West Germany (prior to unification), we do not include estimates for Sweden, for which we were unable to obtain quarterly income data, and we do not include estimates for the United States, which has been covered extensively by Shea. ${ }^{14}$ Estimates of expected income growth were formed by regressing actual income growth at time $t$ against the second through fourth lags of consumption growth, income growth, ex post real interest rates, and an error correction term formed from the second lag of the difference between consumption and income. Since our Japanese data were expressed in annual growth rates, we used the fifth through seventh lags of consumption growth, income growth, ex post real interest rates, and the average fifth through eighth lags of the difference between consumption and income in that case.

Table 1 presents our estimates of the Campbell-Mankiw model for each country. Although the sample periods have been extended, our estimates of $\lambda$ are comparable to those found in Campbell and Mankiw (1991), and our estimate for West Germany is comparable to the estimate formed using GDP as a proxy for personal income found in Campbell and Mankiw (1989).

\footnotetext{
${ }^{14}$ Consumption data come from the OECD Quarterly National Accounts, and income data are taken from the BIS data tapes. Consumption is services and non-durables consumption for all countries but West Germany, for which only aggregate consumption data were available. Where quarterly population numbers were unavailable from the BIS, data were converted to per-capita form using annual population figures from the IMF International Financial Statistics and log-linearly interpolating under the assumption that the annual data were measured in the middle of each year. Real personal disposable income was calculated using the total personal consumption deflator for each country. All data are seasonally adjusted with the exception of Japan; in order to remove seasonality we converted all Japanese data to annual growth rates.

As expenditure on durables differs from consumption of the services provided by durables, the inclusion of durables in our West German data could bias the results. To gauge the importance of this, we re-ran our regression for each of the four other countries and the United States using total consumption. In each case the inclusion of durables' consumption had little impact on our replication of Campbell and Mankiw's results, and either weakened or overturned any evidence of asymmetric behavior in our tests of the Shea model. Based on this, it appears that our finding of asymmetric behavior for West Germany is not due to the inclusion of durables.
} 
Table 2

Estimates of the model

\begin{tabular}{|c|c|c|c|c|c|}
\hline \multirow[t]{2}{*}{ Country } & \multirow[t]{2}{*}{ Obs. } & \multicolumn{3}{|l|}{ Quarters } & \multirow{2}{*}{$\begin{array}{l}p \text {-value } \\
\lambda_{1}=\lambda_{2}\end{array}$} \\
\hline & & $\Delta \ln \hat{y}_{t}<0$ & $\lambda_{1}$ & $\lambda_{2}$ & \\
\hline Canada & 86 & 21 & $0.270(1.59)$ & $1.128(3.14)$ & 0.067 \\
\hline France & 78 & 13 & $0.046(0.22)$ & $1.045(2.33)$ & 0.080 \\
\hline West Germany & 114 & 5 & $0.412(1.91)$ & $3.805(2.12)$ & 0.074 \\
\hline Japan & 75 & 0 & $-0.269(-0.89)$ & - & - \\
\hline United Kingdom & 118 & 13 & $0.356(1.58)$ & $0.651(1.24)$ & 0.649 \\
\hline Panel & 471 & 52 & $0.155(3.79)$ & $1.136(5.21)$ & 0.003 \\
\hline
\end{tabular}

The third and fourth columns present the adjusted $\bar{R}^{2}$ statistics from regressions of consumption and income growth against the instruments used to form expected income growth. The $\bar{R}^{2}$ statistics are not high, but are comparable to those reported in Campbell and Mankiw (1991), and, as can be seen by the $t$-statistics reported in parentheses, do not prevent us from finding statistically significant estimates of $\lambda$ for all countries but Japan. ${ }^{15}$

Table 2 presents our estimates of the Shea model using the same data set ( $t$-statistics again reported in parentheses).

Since there were no quarters in which expected Japanese income growth was negative using our instrument set, an estimate of $\lambda_{2}$ could not be formed in that case. However, for each of the four other countries the point estimate of $\lambda_{2}$ is substantially larger than the point estimate for $\lambda_{1}$, indicating a larger response of consumption to predictable declines in income than to predictable income growth. The last column of Table 2 reports the $p$-value of a $t$-test of the hypothesis that $\lambda_{1}=\lambda_{2}$; this hypothesis can be rejected for all countries but the United Kingdom at the 10 percent level.

Since there are relatively few quarters in which expected income growth is negative in each country, there may be more power in conducting a joint test of this hypothesis rather than an individual test for each country. The last row presents the results when observations are pooled across countries and the hypothesis that $\lambda_{2}>\lambda_{1}$ is tested in a second-stage panel regression with group effects. As can be seen, we are able to reject the hypothesis that $\lambda_{1}=\lambda_{2}$ in favor of the hypothesis that $\lambda_{2}>\lambda_{1}$ at the 1 percent level. $^{16}$

In conjunction with the evidence presented by Shea, the evidence presented here is supportive of the asymmetric behavior predicted by our model.

\footnotetext{
${ }^{15}$ All $t$-tests reported in this section employ consistent estimates of error variances under the null hypothesis, so that they are asymptotically valid in the presence of generated regressors (see Pagan, 1984).

${ }^{16}$ Following Shea and Campbell and Mankiw, we checked the robustness of these results to changes in the instrument set. Experiments which individually added nominal rates, subtracted real rates, subtracted income, or subtracted consumption to/from the instrument set led to similar results. In only one case did the panel results fail to reject the null in favor of the alternative at the 10 percent level, and only in two cases were there individual country estimates in which $\lambda_{1} \geq \lambda_{2}$.
} 


\section{Discussion and conclusion}

This paper provides theoretical and empirical support for an asymmetry in consumption behavior. This asymmetry is due largely to the risk-loving attitude towards losses, which strongly differentiates our model from both classical utility theory and recent literature on habit formation. The habit formation literature in particular assumes that utility is concave in both consumption and the reference point, thus ruling out loss aversion. In these models there is no asymmetry: Consumption adjusts equally slowly to good and bad news about income.

Our exploration of the consumption/saving problem calls for a few natural extensions. We would like to extend the analysis to a multiple-period or infinite-horizon model. To do this, we would need to add discounting and positive interest rates to the model. Given our analysis, we can make an informed guess about how these extensions would change our results. No matter how many periods there are, for instance, it is straightforward to show that if $\alpha=0$, then an agent will never consume below his reference point unless his income absolutely forces him to. As $\alpha$ rises, a consumer will be more willing to consume below his reference point, just as in the two-period model.

Extending the analysis to many periods would also allow us to explore some issues that cannot be completely addressed within the two-period framework. As we show in Proposition 5, consumers may respond to an increase in income uncertainty by either saving more or less, depending on whether expected per-period income is above or below the reference level. Given that losses are costly, it is natural to suppose that over a longer time-frame consumers will plan their consumption path to avoid losses, and that the consumer's typical response to small increases in uncertainty might therefore be to increase savings.

We feel that loss aversion can usefully be incorporated into areas of economic research other than consumption and saving. Benartzi and Thaler (1995) invoke loss aversion to explain under-investment in risky assets. And Shefrin and Statman (1985) find that trading volume on the stock market falls when stock values fall, which they attribute to loss aversion - investors are unwilling to realize losses on their investments and so hold on to their stocks. Fershtman (1993) considers the effect of loss aversion on the willingness of industry incumbents to fight potential entrants. Formal modeling along the lines developed in this paper may help researchers begin to systematically investigate the implications of loss aversion in a wider array of economic situations.

\section{Acknowledgements}

International Finance Division of the Board of Governors of the Federal Reserve System, Boston University, and the University of California at Berkeley, respectively. This paper represents the views of the authors and should not be interpreted as reflecting the views of the Board of Governors of the Federal Reserve System or other members of its staff. We thank two anonymous referees, Colin Camerer, Richard Day, Eddie DekelTabak, Erik Eyster, Simon Gilchrist, John Hey, Danny Kahneman, Halsey Rogers, David 
Romer, and Richard Thaler for helpful comments. We are also grateful to Berkeley's Institute for Business and Economic Research for funding of research assistance. Matthew Rabin thanks the National Science Foundation for financial support, through research grant SES-9210323.

\section{Appendix A}

Note: In all proofs, we denote the function $v(x)$ by $v_{1}(x)$ when $x \leq 0$, and by $v_{\mathrm{g}}(x)$ when $x \geq 0$.

\section{A.1. Proof of Proposition 1}

Assumption A4 implies that there exist $\delta>0, \gamma>0$ such that

$$
v_{l}^{\prime}(y)-v_{\mathrm{g}}^{\prime}(0)>\gamma>0
$$

for all $y \in(-\delta, 0]$. Let $F$ and $G$ denote the c.d.f.'s of $f$ and $g$, and let $y_{i}$ be the lowest $y$ realized with positive probability by either $f$ or $g$. Set $\epsilon \equiv-\delta / y_{i}$. Then $k<\epsilon$ implies that

$$
\begin{aligned}
E\{v(k g)\}= & \int_{y_{i}}^{0} v_{l}(k x) \mathrm{d} G(x)+\int_{0}^{\infty} v_{\mathrm{g}}(k x) \mathrm{d} G(x)=\int_{y_{i}}^{0}\left[\int_{0}^{x} v_{l}^{\prime}(k s) \mathrm{d} s\right] \mathrm{d} G(x) \\
& +\int_{0}^{\infty}\left[\int_{0}^{x} v_{\mathrm{g}}^{\prime}(k s) \mathrm{d} s\right] \mathrm{d} G(x)<\int_{y_{i}}^{0}\left[v_{\mathrm{g}}^{\prime}(0)+\gamma\right] x \mathrm{~d} G(x)+\int_{0}^{\infty} v_{\mathrm{g}}^{\prime}(0) x \mathrm{~d} G(x) \\
= & v_{\mathrm{g}}^{\prime}(0) \int_{1 / 2}^{\infty} x \mathrm{~d} G(x)+\gamma \int_{y_{i}}^{0} x \mathrm{~d} G(x)=\gamma \int_{y_{i}}^{0} x \mathrm{~d} G(x)<0,
\end{aligned}
$$

and it implies that

$$
\begin{aligned}
E\{v(k f)\} & =\int_{y i}^{0} v_{l}(k x) \mathrm{d} F(x)+\int_{0}^{\infty} v_{\mathrm{g}}(k x) \mathrm{d} F(x)<v_{\mathrm{g}}^{\prime}(0)\left[\int_{y_{i}}^{0} x \mathrm{~d} F(x)+\int_{0}^{\infty} x d F(x)\right] \\
& =v_{\mathrm{g}}^{\prime}(0) \int_{y_{i}}^{\infty} x \mathrm{~d} F(x) .
\end{aligned}
$$

Set $a(p) \equiv p v_{\mathrm{g}}^{\prime}(0) \int_{y_{i}}^{\infty} x d F(x)+(1-p) \gamma \int_{y_{i}}^{0} x d G(x)$. Then $a(1)>0$, since $f$ is better-thanfair, and $a(0)<0$. Thus, there exists $p^{*}>0$ such that $a\left(p^{*}=0\right)$ and $a(p)<0$ for all $p<p^{*}$. So $p<p^{*}$ and $k<\epsilon$ imply that

$$
E\{v(k h(p))\}=p E\{v(k f)\}+(1-p) E\{v(k g)\} .
$$

But this is less than $a(p)$, which is negative, so $h(p)$ is rejected when scaled by $k<\epsilon$. QED

Remark on Proposition 2. This proposition would also be true even if the supports of $f$ and $g$ contained infinitely negative outcomes, so long as the expected value of losses were finite for each of the bets. 


\section{A.2. Proof of Theorem 1}

For any given $r_{1}$ and $Y$, substituting $Y-c_{1}$ for $c_{2}$ and $\alpha c_{1}+(1-\alpha) r_{1}$ for $r_{2}$, we can write $U\left(c_{1}, r_{1} ; c_{2}, r_{2}\right)$ as a function of $c_{1}$ alone:

$$
u\left(c_{1}\right) \equiv w\left(r_{1}\right)+v\left(c_{1}-r_{1}\right)+w\left(\alpha c_{1}+(1-\alpha) r_{1}\right)+v\left(Y-(1+\alpha) c_{1}-(1-\alpha) r_{1}\right)
$$

We will let $c_{1}^{*}$ denote the $c_{1} \in[0, Y]$ that maximizes $u\left(c_{1}\right)$, and let $c_{2}^{*} \equiv Y-c_{1}^{*}$.

(i) We first prove that $\left(c_{1}^{*}-r_{1}\right)\left(c_{2}^{*}-r_{2}\right) \geq 0$. Note that this implies that $c_{1}^{*}=c_{2}^{*}=r_{1}$ when $Y=2 r_{1}$.

If $c_{1}>r_{1}$ and $c_{2}<r_{2}$, then

$$
u^{\prime}\left(c_{1}\right)=v_{\mathrm{g}}^{\prime}\left(c_{1}-r_{1}\right)+\alpha w^{\prime}\left(r_{2}\right)-(1+\alpha) v_{1}^{\prime}\left(Y-c_{1}-r_{2}\right) .
$$

By either $\mathrm{B} 1-\mathrm{B} 2$ or $\mathrm{C}$ this is negative, so that the consumer will decrease $c_{1}$.

If $c_{1}<r_{1}$ and $c_{2}>r_{2}$, then

$$
u^{\prime}\left(c_{1}\right)=v_{1}^{\prime}\left(c_{1}-r_{1}\right)+\alpha w^{\prime}\left(r_{2}\right)-(1+\alpha) v_{\mathrm{g}}^{\prime}\left(Y-c_{1}-r_{2}\right) .
$$

By either $\mathrm{A} 5$ and $\mathrm{B} 1$ or $\mathrm{C}$ this is positive, so that the consumer will increase $c_{1}$.

(ii) We prove that $c_{1}^{*}$ and $c_{2}^{*}$ are continuous and non-decreasing if $Y \geq 2 r_{1}$.

Assume $Y \geq 2 r_{1}$. We know from (i) that $c_{1}^{*} \geq r_{1}$ and $c_{2}^{*} \geq r_{2}$. This implies $r_{1} \leq c_{1}^{*} \leq Y-(1-\alpha) r_{1} / 1+\alpha . u\left(c_{1}\right)$ is strictly concave in this region, so that there is a unique solution for $c_{1}^{*}$.

If

$$
u^{\prime}\left(r_{1}\right)=v_{\mathrm{g}}^{\prime}(0)+\alpha w^{\prime}\left(r_{1}\right)-(1+\alpha) v_{\mathrm{g}}^{\prime}\left(Y-2 r_{1}\right)<0,
$$

then $c_{1}^{*}=r_{1}$ and $c_{2}^{*}=Y-r_{1}$. As $Y$ increases, $u^{\prime}\left(r_{1}\right)$ increases continuously by the assumptions that $v_{\mathrm{g}}$ and $w$ are concave and twice continuously differentiable.

If

$$
u^{\prime}\left(\frac{Y-(1-\alpha) r_{1}}{1+\alpha}\right)=v_{\mathrm{g}}^{\prime}\left(\frac{Y-2 r_{1}}{1+\alpha}\right)+\alpha w^{\prime}\left(\frac{\alpha Y+(1-\alpha) r_{1}}{1+\alpha}\right)-(1+\alpha) v_{\mathrm{g}}^{\prime}(0)>0
$$

then $c_{1}^{*}=\left(Y-(1-\alpha) r_{1}\right) /(1+\alpha)$ and $c_{2}^{*}=\left(\alpha Y+(1-\alpha) r_{1}\right) /(1+\alpha) \cdot u^{\prime}\left(\left(Y-(1-\alpha) r_{1}\right) /\right.$ $(1+\alpha))$ decreases continuously as $Y$ increases by the assumptions that $v_{\mathrm{g}}$ and $w$ are concave and twice continuously differentiable.

If neither of these holds, then there is a $\bar{c}_{1} \in\left[r_{1}, Y-(1-\alpha) r_{1} / 1+\alpha\right]$ such that $u^{\prime}\left(\bar{c}_{1}\right)=0$. In this case $c_{1}^{*}=\bar{c}_{1}$ and $c_{2}^{*}=Y-\bar{c}_{1}$. We know $\bar{c}_{1}$ is a continuous function of $Y$ since $v_{g}^{\prime}$ and $w^{\prime}$ are continuous. Totally differentiating the equation $u^{\prime}\left(\bar{c}_{1}\right)=0$ yields $1 /(1+\alpha)>\mathrm{d} \bar{c}_{1} / \mathrm{d} Y>0$.

(iii) We prove that $c_{1}^{*}$ and $c_{2}^{*}$ are continuous and non-decreasing if $Y<2 r_{1}$.

Assume that $Y<2 r_{1}$. From (i), we know that $c_{1}^{*} \leq r_{1}$ and $c_{2}^{*} \leq r^{2}$, so that $\left(Y-(1-\alpha) r_{1}\right) /(1+\alpha) \leq c_{1}^{*} \leq r_{1}$. If $\alpha=0$ then by the convexity of $v_{1}$, the consumer will choose either $c_{1}^{*}=\max \left[r_{1}, Y\right]$ or $c_{2}^{*}=\max \left[r_{1}, Y\right]$, and will be indifferent between these two choices. Either solution satisfies the claim of Theorem 1.

Now suppose that $\alpha>0$. Consider $\left.c_{1} \in\left(\left(Y+\alpha r_{1}\right) /(2+\alpha), r_{1}\right)\right)$. In this region we have $0 \geq c_{1}-r_{1}>c_{2}-r_{2}$, which can be rewritten as $\left(Y-2 r_{1}\right) /(2+\alpha)<c_{1}-r_{1} \leq 0$. 
The choice of any $c_{1}-r_{1} \equiv z$ in this range yields a level of utility equal to

$$
u\left(r_{1}+z\right)=v_{1}(z)+w\left(\alpha z+r_{1}\right)+v_{1}\left(Y-(1+\alpha) z-2 r_{1}\right) .
$$

Compare this to the choice of $c_{2}-r_{2}=z$ (This choice implies a $c_{1}$ which lies in the range $\left.c_{1} \in\left[\left(Y-(1-\alpha) r_{1}\right) /(1+\alpha),\left(Y+\alpha r_{1}\right) /(2+\alpha)\right]\right)$. If $c_{1}=r_{1}+z$ is feasible, then $c_{2}=r_{2}+z$ is also feasible. The choice $c_{2}=r_{2}+z$ results in utility

$$
u\left(Y-r_{2}-z\right)=v_{1}\left(Y-(1+\alpha) z-2 r_{1}+k\right)+w\left(\alpha z+r_{1}-k\right)+v_{1}(z),
$$

where $k \equiv \alpha\left[2 r_{1}-Y+(2+\alpha) z\right] /(1-\alpha)>0$. Comparing the two choices,

$$
\begin{aligned}
& u\left(Y-r_{2}-z\right)-u\left(r_{1}+z\right)=\left[v_{1}\left(Y-(1+\alpha) z-2 r_{1}+k\right)-v_{1}\left(Y-(1+\alpha) z-2 r_{1}\right)\right] \\
& \quad+\left[w\left(\alpha z+r_{1}-k\right)-w\left(\alpha z+r_{1}\right)\right] .
\end{aligned}
$$

Either B2 or C imply that $v_{l}(x+q)-v_{l}(x)>w(s+q)-w(s)$ for any $q>0, x \leq-q$ and $s \geq 0$. Therefore $u\left(Y-r_{2}-z\right)>u\left(r_{1}+z\right)$ for any $z$ such that $\left(Y-2 r_{1}\right) /(2+\alpha)<z \leq 0$. This implies that for any feasible choice of $c_{1} \in\left(\left(Y+\alpha r_{1}\right) /(2+\alpha), r_{1}\right)$ there is a feasible choice of $c_{1} \in\left[\left(Y-(1-\alpha) r_{1}\right) /(1+\alpha),\left(Y+\alpha r_{1}\right) /(2+\alpha)\right]$ which is preferred. Therefore $c_{1}^{*} \in\left[\left(Y-(1-\alpha) r_{1}\right) /(1+\alpha),\left(Y+\alpha r_{1}\right) /(2+\alpha)\right]$. In this region $c_{1}-r_{1} \leq c_{2}-r_{2}$ $\leq 0$, and so we have

$$
u^{\prime}\left(c_{1}\right)=v_{1}^{\prime}\left(c_{1}-r_{1}\right)+\alpha w^{\prime}\left(\alpha c_{1}+(1-\alpha) r_{1}\right)-(1+\alpha) v_{1}^{\prime}\left(c_{2}-r_{2}\right)<0
$$

by A3 and either B2 or C. This implies $c_{1}^{*}=\operatorname{Max}\left[0,\left(Y-(1-\alpha) r_{1}\right) /(1+\alpha)\right]$.

Steps (i), (ii), and (iii) together establish the theorem. QED

Remark on Theorem 1: The proof above shows that $c_{1}(Y)$ is never steeper for $Y / 2>r_{1}$ than it is for $Y / 2<r_{1}$.

\section{A.3. Proof of Proposition 2}

The proof of Theorem 1 established that $c_{1}(Y)$ and $c_{2}(Y)$ were strictly increasing for all values of $Y, r_{1}$, and $\alpha>0$ such that the constraint $c_{t} \geq 0$ was non-binding except when $Y \geq 2 r_{1}$ and

$$
u^{\prime}\left(r_{1}\right)=v_{\mathrm{g}}^{\prime}(0)+\alpha w^{\prime}\left(r_{1}\right)-(1+\alpha) v_{\mathrm{g}}^{\prime}\left(Y-2 r_{1}\right)<0 .
$$

Assumption C rules out such cases. QED

\section{A.4. Proof of Proposition 3}

Define $u\left(c_{1}\right), c_{1}^{*}$, and $c_{2}^{*}$ as in the proof to Theorem 1 .

\section{A.4.1. Part (i)}

Suppose that there is some $\bar{r} \geq 0, \bar{c} \geq \bar{r}$, such that $v^{\prime}(\bar{c}-\bar{r}) \geq w^{\prime}(\bar{r})$. Then by A3 and A5, for any $r>\bar{r}$ and $\bar{c} \geq c>r$ we have $v^{\prime}(c-r)>w^{\prime}(r)$. Choose an $r$ satisfying these constraints, and let $r_{1}=r, Y \geq 2 r_{1}$.

Theorem 1 implies that $c_{1} \geq r$ and $c_{2} \geq r$. If $c_{1}=r$ then

$$
u^{\prime}(r)=v_{\mathrm{g}}^{\prime}(0)+\alpha w^{\prime}(r)-(1+\alpha) v_{\mathrm{g}}^{\prime}(Y-2 r)
$$


and $\lim _{Y \rightarrow 2 r_{1}} u^{\prime}(r)=\alpha\left[w^{\prime}(r)-v_{\mathrm{g}}^{\prime}(0)\right]<0$. As $v_{g}^{\prime}$ and $w^{\prime}$ are continuous, this implies that there is some $x>0$ such that for all $0<y \leq x, u^{\prime}(r)=v_{\mathrm{g}}^{\prime}(0)+\alpha w^{\prime}(r)-(1+\alpha) v_{\mathrm{g}}^{\prime}(y)$ $<0$.

$u\left(c_{1}\right)$ is concave in the region $r \leq c_{1} \leq(Y-(1-\alpha) r) /(1+\alpha)$. Therefore if $c_{1}^{*}$ lies in this region, $c_{1}^{*}=r$ for $Y \in[2 r, 2 r+x]$. This means $c_{1}(Y)$ is not strictly increasing in this region. To see that $c_{1} \in[r,(Y-(1-\alpha) r) /(1+\alpha)]$ note that by supposition $r \leq c_{1}^{*} \leq Y-r$ and if $c_{1}>(Y-(1-\alpha) r) /(1+\alpha)$ then $c_{2}<r_{2}$, which violates the claim of Theorem 1 that $\left(c_{1}-r_{1}\right)\left(c_{2}-r_{2}\right) \geq 0$.

This proves that Theorem 1, A1-A5, and the statement that $c_{1}(Y)$ and $c_{2}(Y)$ are strictly increasing for all $Y$ and $r_{1}$ such that the constraint $c_{t} \geq 0$ is non-binding imply $w^{\prime}(r)>v^{\prime}(c-r)$ for any $r \geq 0$ and $c \geq r$. Given that $w$ and $v_{\mathrm{g}}$ are strictly concave, this can be true if and only if $U(c, c)>U(r, c)$ for any $r \geq 0$ and $c>r$.

\section{A.4.2. Part (ii)}

Consider $Y \leq 2 r_{1}$. By supposition $c_{1}^{*} \leq r_{1}$ and $c_{2}^{*} \leq r_{1}$. Note that if $c_{1}<(Y-$ $\left.(1-\alpha) r_{1}\right) /(1+\alpha)$ then $c_{2}>r_{2}$, which violates the claim of Theorem 1 that $\left(c_{1}-r_{1}\right)\left(c_{2}-r_{2}\right) \geq 0$.

Over the range $\left(Y-(1-\alpha) r_{1}\right) /(1+\alpha) \leq c_{1} \leq r_{1}$

$$
u^{\prime}\left(c_{1}\right)=v_{1}^{\prime}\left(c_{1}-r_{1}\right)+w^{\prime}\left(\alpha c_{1}+(1-\alpha) r_{1}\right)+v_{1}^{\prime}\left(Y-(1-\alpha) r_{1}-(1+\alpha) c_{1}\right)
$$

In this region $u\left(c_{1}\right)$ need be neither concave nor convex. Suppose $c_{1}^{*}$ is in the interior of this region. For this to be so, $u\left(c_{1}\right)$ must be concave in some neighborhood of $c_{1}^{*}$. At such an optimum we must have $u^{\prime}\left(c_{1}^{*}\right)=0$. Totally differentiating this equation with respect to $c_{1}^{*}$ and $Y$ implies that

$$
\frac{\mathrm{d} c_{1}^{*}}{\mathrm{~d} Y}=\frac{(1+\alpha) v_{1}^{\prime \prime}\left(Y-(1-\alpha) r_{1}-(1+\alpha) c_{1}^{*}\right)}{u^{\prime \prime}\left(c_{1}^{*}\right)}<0,
$$

which contradicts the claim that $c_{1}(Y)$ is strictly increasing. Therefore there can be no interior optimum, which implies that either $c_{1}^{*}=r_{1}$ or $c_{1}^{*}=\left(Y-(1-\alpha) r_{1}\right) /(1+\alpha)$. Since $c_{1}^{*}=r_{1}$ also violates the claim that $c_{1}(Y)$ is strictly increasing, we must have $c_{1}^{*}=\left(Y-(1-\alpha) r_{1}\right) /(1+\alpha)$. This implies that $u\left(Y-(1-\alpha) r_{1} / 1+\alpha\right) \geq u\left(c_{1}\right)$ for any $c_{1}$. In particular we must have $X \equiv u\left(\left(Y-(1-\alpha) r_{1}\right) /(1+\alpha)\right)-u\left(r_{1}\right)$ $>0$ if $Y<2 r_{1}$. Writing out the terms of $X$ we have:

$$
X \equiv v_{1}\left(\frac{Y-2 r_{1}}{1+\alpha}\right)+w(z)-w(z+k)-v_{1}\left(\frac{Y-2 r_{1}}{1+\alpha}-k\right)>0,
$$

where $k=\alpha\left(2 r_{1}-Y\right) /(1+\alpha)>0$, and $z=r_{1}-k$. Since

$$
\left.v_{1}(0)-v_{1}(-k)\right]>\left[v_{1}\left(\frac{Y-2 r_{1}}{1+\alpha}\right)-v_{1}\left(\frac{Y-2 r_{1}}{1+\alpha}-k\right)\right],
$$

$X>0$ for any $r_{1} \geq 0$ and $Y<2 r_{1}$ implies $-v_{1}(-k)>w(z+k)-w(z)$ for any $k>0, z \geq 0$. This last inequality implies $U(c, c)>U(r, c)$ for any $c \geq 0$ and $r>c$. QED 


\section{A.5. Proof of Theorem 2}

We prove the proposition for lotteries that are represented by probability measures of the form $\mathbf{m}=\mathbf{f} \lambda+\mathbf{d}$, where $\lambda$ is Lebesgue measure on $\mathbf{R}, \mathbf{f}: \mathbf{R} \rightarrow \mathbf{R}$ is a measurable function, and $\boldsymbol{d}$ is a measure which has support consisting of a countable collection of point masses with no point of accumulation.

The proof has two parts. First we show the theorem holds for binomial bets in which $Y_{2}$ takes on only two values, $Y_{H}$ and $Y_{L}$. Then we show that bets of this type can be combined, to yield the result for all $Y$ in the class described above.

\section{A.5.1. Part I of proof}

Suppose $Y_{2}$ is such that $P\left[Y_{2}=Y_{H}\right]=p, P\left[Y_{2}=Y_{L}\right]=1-p$, where $\left(Y_{1}+Y_{H}\right) / 2 \geq r_{1}$ and $p \geq \alpha /(1+\alpha)$ if $\mathrm{C}$ holds and $p \geq 2 \alpha /(1+\alpha)$ if B1-B2 hold. For binomial bets $Y_{2}$, this is equivalent to the hypothesis of the proposition. We show that $c_{1} \geq r_{1}$. To prove this, we consider two cases:

Case 1 of Part I: $\left(Y_{1}+Y_{L}\right) / 2 \geq r_{1}$.

Substituting $Y_{1}+Y_{2}-c_{1}$ for $c_{2}$ and $(1-\alpha) r_{1}+c_{1}$ for $r_{2}$, we can write expected lifetime utility as a function of $c_{1}$ alone:

$$
\begin{aligned}
u\left(c_{1}\right)= & w\left(r_{1}\right)+v\left(c_{1}-r_{1}\right)+w\left((1-\alpha) r_{1}+\alpha c_{1}\right)+p v\left(Y_{1}+Y_{H}-\left((1-\alpha) r_{1}\right.\right. \\
& \left.+(1+\alpha) c_{1}\right)+(1-p) v\left(Y_{1}+Y_{L}-\left((1-\alpha) r_{1}+(1+\alpha) c_{1}\right)\right)
\end{aligned}
$$

Then $c_{1}<r_{1}$ implies, by either $\mathrm{A} 5$ and $\mathrm{B} 1$ or $\mathrm{C}$, that

$$
\begin{aligned}
u^{\prime}\left(c_{1}\right)= & v_{1}^{\prime}\left(c_{1}-r_{1}\right)+\alpha w^{\prime}\left((1-\alpha) r_{1}+\alpha c_{1}\right)-p(1+\alpha) v_{\mathrm{g}}^{\prime}\left(Y_{1}+Y_{H}-\left((1-\alpha) r_{1}\right.\right. \\
& \left.+(1+\alpha) c_{1}\right)-(1-p)(1+\alpha) v_{\mathrm{g}}^{\prime}\left(Y_{1}+Y_{L}-\left((1-\alpha) r_{1}+(1+\alpha) c_{1}\right)\right)
\end{aligned}
$$

is greater than zero. Thus maximization in $c_{1}$ implies $c_{1} \geq r_{1}$.

Case 2 of Part I: $\left(Y_{1}+Y_{H}\right) / 2 \geq r_{1}>\left(Y_{1}+Y_{L}\right) / 2$.

(i) $c_{1}<\min \left\{r_{1}, Y_{1}+Y_{L}-(1-\alpha) r_{1} / 1+\alpha\right\}$ :

$$
\begin{aligned}
u^{\prime}\left(c_{1}\right)= & v_{1}^{\prime}\left(c_{1}-r_{1}\right)+\alpha w^{\prime}\left((1-\alpha) r_{1}+\alpha c_{1}\right)-p(1+\alpha) v_{\mathrm{g}}^{\prime}\left(Y_{1}+Y_{H}-\left((1-\alpha) r_{1}\right.\right. \\
& \left.+(1+\alpha) c_{1}\right)-(1-p)(1+\alpha) v_{\mathrm{g}}^{\prime}\left(Y_{1}+Y_{L}-\left((1-\alpha) r_{1}+(1+\alpha) c_{1}\right)\right)
\end{aligned}
$$

is greater than zero by either assumptions $\mathrm{A} 5$ and $\mathrm{B} 1$ or $\mathrm{C}$.

(ii) $r_{1} \geq c_{1} \geq\left(Y_{1}+Y_{L}-(1-\alpha) r_{1}\right) /(1+\alpha)$ :

Let $u\left(c_{1}\right)=x_{1}+x_{2}$, where

$$
\begin{gathered}
x_{1}\left(c_{1}\right)=(1-p)(1+\alpha) v_{1}\left(c_{1}-r_{1}\right)+(1-p) v_{1}\left(Y_{1}+Y_{L}-\left((1-\alpha) r_{1}+(1+\alpha) c_{1}\right)\right) \\
x_{2}\left(c_{1}\right)=[1-(1-p)(1+\alpha)] v_{1}\left(c_{1}-r_{1}\right)+w\left((1-\alpha) r_{1}+\alpha c_{1}\right) \\
+p v_{\mathrm{g}}\left(Y_{1}+Y_{H}-\left((1-\alpha) r_{1}+(1+\alpha) c_{1}\right)\right)
\end{gathered}
$$

Then if $c_{1}<r_{1}$

$$
\begin{aligned}
x_{2}^{\prime}\left(c_{1}\right)= & {[(1+\alpha) p-\alpha] v_{1}^{\prime}\left(c_{1}-r_{1}\right)+\alpha w^{\prime}\left((1-\alpha) r_{1}+\alpha c_{1}\right) } \\
& -(1+\alpha) p v_{\mathrm{g}}^{\prime}\left(Y_{1}+Y_{H}-\left((1-\alpha) r_{1}+(1+\alpha) c_{1}\right)\right)
\end{aligned}
$$


If $\mathrm{C}$ holds then

$x_{2}^{\prime}\left(c_{1}\right)>[(1+\alpha) p-\alpha] v_{1}^{\prime}\left(c_{1}-r_{1}\right)-[(1+\alpha) p-\alpha] v_{\mathrm{g}}^{\prime}\left(Y_{1}+Y_{H}-\left((1-\alpha) r_{1}+(1+\alpha) c_{1}\right)\right)$

which is non-negative by A5, since $p \geq \alpha / 1+\alpha$. If instead B1-B2 hold, note that

$$
x_{2}^{\prime}\left(c_{1}\right)>[(1+\alpha) p-\alpha] v_{1}^{\prime}\left(c_{1}-r_{1}\right)-(1+\alpha) p v_{\mathrm{g}}^{\prime}\left(Y_{1}+Y_{H}-\left((1-\alpha) r_{1}+(1+\alpha) c_{1}\right)\right)
$$

and that therefore $x_{2}^{\prime}\left(c_{1}\right)>0$ if $p \geq 2 \alpha /(1+\alpha)$. So $x_{2}$ is maximized in this region at $c_{1}=r_{1}$.

$x_{1}^{\prime}\left(c_{1}\right)=(1-p)(1+\alpha) v_{1}^{\prime}\left(c_{1}-r_{1}\right)-(1-p)(1+\alpha) v_{1}^{\prime}\left(Y_{1}+Y_{L}-\left((1-\alpha) r_{1}+(1+\alpha) c_{1}\right)\right)$ $x_{1}^{\prime \prime}\left(c_{1}\right)=(1-p)(1+\alpha) v_{1}^{\prime \prime}\left(c_{1}-r_{1}\right)+(1-p)(1+\alpha)^{2} v_{1}^{\prime \prime}\left(Y_{1}+Y_{L}-\left((1-\alpha) r_{1}+(1+\alpha) c_{1}\right)\right)$

Since $x_{1}^{\prime}\left(c_{1}\right)>0, x_{1}$ is convex in this region and it therefore has exactly two local maxima, at $c_{1}=r_{1}$ and at $c_{1}=\left(Y_{1}+Y_{L}-(1-\alpha) r_{1}\right) /(1+\alpha)$, respectively. But by A3

$$
\begin{aligned}
& x_{1}\left(\frac{Y_{1}+Y_{L}-(1-\alpha) r_{1}}{1+\alpha}\right)=(1-p)(1+\alpha) v_{1}\left(\frac{Y_{1}+Y_{L}-2 r_{1}}{1+\alpha}\right) \\
& \quad<(1-p) v_{1}\left(Y_{1}+Y_{L}-2 r_{1}\right)=x_{1}\left(r_{1}\right)
\end{aligned}
$$

Thus $x_{1}$ is strictly maximized over the region at $c_{1}=r_{1}$. Since $x_{1}$ and $x_{2}$ are both maximized at $c_{1}=r_{1}, u\left(c_{1}\right)$ is strictly maximized over $\left[Y_{1}+Y_{L}-(1-\alpha) r_{1} / 1+\alpha, r_{1}\right]$ at $c_{1}=r_{1}$ Case 1 and Case 2 imply that utility is maximized at $c_{1} \geq r_{1}$.

\section{A.5.2. Part II of the proof}

Case 1 of Part II: Suppose $Y_{2}$ is a countable sum of point masses with no accumulation point:

$$
Y_{2}=\sum_{i=1}^{N_{+}} p_{i} \delta_{x_{i}}+\sum_{j=1}^{N_{-}} q_{j} \delta_{y_{j}}
$$

where $p_{i}, q_{j}>0, x_{i} \geq 0, y_{j}<0, N_{+}, N_{-} \in \mathbb{N} \cup\{\infty\}$, and $i>i^{\prime}, j>j^{\prime} \Rightarrow x_{i}>x_{i^{\prime}}, y_{j}<y_{j^{\prime}}$.

Claim: Because $P\left[Y \geq 2 r_{1}\right] \geq \alpha /(1+\alpha)$, we can rewrite $Y_{2}$ in the form

$$
Y_{2}=\sum_{i=1}^{M} \tilde{p}_{i} \delta_{\tilde{x}_{i}}+\sum_{i=1}^{M}\left(\frac{\tilde{p}_{i}}{\alpha_{i}}\right) \delta_{\tilde{y}_{i}}+\sum_{j=1}^{Q} \tilde{S}_{j} \delta_{\tilde{z}_{j}},
$$

where $\tilde{z}_{i}, \tilde{x}_{i} \geq 0, \tilde{y}_{i}<0, \tilde{z}_{1} \geq \tilde{x}_{M}$, and $i>j \Rightarrow \tilde{x}_{i}>\tilde{x}_{j}, \tilde{z}_{i}>\tilde{z}_{j}, \tilde{y}_{i}<\tilde{y}_{j}$.

Proof of Claim: The proof of this is tedious, but straightforward. Match successively lower outcomes with successively higher outcomes in the proportion of $1 / \alpha$ to 1 . Because the support of $Y_{2}$ has no point of accumulation, this countable process eventually exhausts all of the negative weight of $Y_{2}$. Then

$$
Y_{2}=\sum_{i=1}^{M}\left(1+\frac{1}{\alpha}\right) \tilde{p}_{i}\left[\frac{\alpha}{1+\alpha} \delta_{\tilde{x}_{i}}+\frac{1}{1+\alpha} \delta_{\tilde{y}_{i}}\right]+\sum_{j=1}^{Q} \tilde{S}_{j} \delta_{\tilde{z}_{j}},
$$

Each term in brackets [] is a binomial bet (the $\delta_{\tilde{z}_{j}}$ are trivially so) satisfying the hypothesis of Theorem 2. 
Expected lifetime utility can be written as

$$
\begin{aligned}
u\left(c_{1}\right)= & \sum_{i=1}^{M}\left(1+\frac{1}{\alpha}\right) \tilde{p}_{i}\left[w\left(r_{1}\right)+v\left(c_{1}-r_{1}\right)+w\left(r_{2}\right)+\frac{1}{1+\alpha} v\left(Y_{1}+\tilde{y}_{i}\right.\right. \\
& \left.\left.-\left((1-\alpha) r_{1}+(1+\alpha) c_{1}\right)\right)+\frac{\alpha}{1+\alpha} v\left(Y_{1}+\tilde{x}_{i}-\left((1-\alpha) r_{1}+(1+\alpha) c_{1}\right)\right)\right] \\
& +\sum_{j}^{Q} \tilde{S}_{j}\left[w\left(r_{1}\right)+v\left(c_{1}-r_{1}\right)+w\left(r_{2}\right)+v\left(Y_{1}+\tilde{z}_{j}-\left((1-\alpha) r_{1}+(1+\alpha) c_{1}\right)\right)\right]
\end{aligned}
$$

From Part 1, we know that each square bracketed term in this expression takes on a larger value at $c_{1}=r_{1}$ than at $c_{1}<r_{1}$. But this implies that $u\left(r_{1}\right)>u\left(c_{1}\right)$ for $c_{1}<r_{1}$, and hence that utility is maximized at $c_{1} \geq r_{1}$.

Case 2 of Part II: Suppose $Y_{2}$ has a density with respect to Lebesgue measure in the sense that there is a measurable function $\mathbf{h}$ such that $P\left[Y_{2} \geq x\right]=\int_{x}^{\infty} h(x) d x$. Further suppose $\int_{\left(2 r_{1}-Y_{1}\right)}^{\infty} h(x) d x \geq \alpha / 1+\alpha$. Let $H(a)=\int_{-\infty}^{a} h(x) d x$ be the cumulative distribution function for $\mathbf{h}$. Define $q(a) \equiv \inf H^{-1}\left[(\alpha+1) H\left(\left(2 r_{1}-Y_{1}\right)\right)-\alpha H(a)\right]$. Then $q$ is increasing and hence measurable and

$$
\alpha \int_{a}^{\left(2 r_{1}-Y_{1}\right)} h(x) d x=\int_{\left(2 r_{1}-Y_{1}\right)}^{q(a)} h(x) d x .
$$

Claim: For measurable $f: \mathbb{R} \rightarrow \mathbb{R}, \alpha \int_{a}^{0} f(q(x)) h(x) d x=\int_{0}^{q(a)} f(x) h(x) d x$.

Proof of Claim: The statement holds for simple functions $f$ (those taking a finite number of values), since we can then break the integrals down into the sum of integrals over regions $\left[a_{i}, b_{i}\right]$ so that $f$ is constant on both $\left[a_{i}, b_{i}\right]$ and $\left[q\left(b_{i}\right), q\left(a_{i}\right)\right]$. On these regions the equalities follow from Eq. (1). Approximate $f$ by simple functions $f_{n}, 0 \leq f_{n} \leq f, 1$, so that $f_{n}(x) \rightarrow f(x)$ for all $x \in \mathbb{R}$. Then we have:

$$
\alpha \int_{a}^{0} f_{n}(q(x)) h(x) d x=\int_{0}^{q(a)} f_{n}(x) h(x) d x .
$$

Since $q$ is increasing, $f_{n}(q(x))$ is a simple function defined on $(-\infty, 0]$. Clearly $0 \leq f_{n}(q(x)) \leq f(q(x))$, and $f_{n}(q(x)) \rightarrow f(q(x))$ for all $x \in(-\infty, 0]$. Applying Lebesgue's theorem of monotone convergence to both sides of the Eq. (2), we are done.

Finally, using the claim, we can rewrite the consumer's problem as choosing $c_{1}$ to maximize

$$
\begin{aligned}
& (1+\alpha) \int_{-\infty}^{\left(2 r_{1}-Y_{1}\right)}\left[w\left(r_{1}\right)+v\left(c_{1}-r_{1}\right)+w\left(r_{2}\right)+\frac{1}{1+\alpha} v\left(Y_{1}+x-c_{1}-r_{2}\right)\right. \\
& \left.+\frac{\alpha}{1+\alpha} v\left(Y_{1}+q(x)-c_{1}-r_{2}\right)\right] h(x) d x+\int_{q(-\infty)}^{\infty}\left[w\left(r_{1}\right)+v\left(c_{1}-r_{1}\right)+w\left(r_{2}\right)\right. \\
& \left.\quad+v\left(Y_{1}+x-c_{1}-r_{2}\right)\right] h(x) d x
\end{aligned}
$$

In the first integral, $Y_{1}+q(x) \geq 2 r_{1}$, while in the second integral, $Y_{1}+x \geq 2 r_{1}$. So each term in brackets [] represents the utility from a binomial lottery on income satisfying 
the hypothesis of Theorem 2, and hence from Part 1 is larger at $c_{1}=r_{1}$ than at any $c_{1}<r_{1}$. That is, utility is maximized at $c_{1} \geq r_{1}$. QED

\section{A.6. Proof of Proposition 4}

The proof is by example. (The examples given are not hard to create.)

\section{A.6.1. Example 1: (Under Condition C)}

$$
\begin{gathered}
U(r, c)= \begin{cases}r+(c-r)-.25(c-r)^{2} & \text { if } c>r \\
r+1.05(c-r)+.0625(c-r)^{2} & \text { if } c \leq r .\end{cases} \\
r_{2}=0.5 r_{1}+0.5 c_{1}
\end{gathered}
$$

where $r_{1}=1,1 \leq Y_{1} \leq 2$ and $Y_{2}$ is uniformly distributed over [0,0.5]. For values of first period income between 1.69 and 1.75 average per-period expected income is less than $r_{1}$, but first period consumption is greater than $r_{1}$.

\section{A.6.2. Example 2 (Under Conditions B1-B2)}

$$
\begin{aligned}
& U(r, c)= \begin{cases}\frac{1}{1-\gamma}\left(b_{\mathrm{g}}+c-r\right)^{1-\gamma}-\frac{1}{1-\gamma} b_{\mathrm{g}} & \text { if } c>r \\
\frac{1}{1-\lambda} b_{l}-\frac{1}{1-\lambda}\left(b_{l}+r-c\right)^{1-\lambda} & \text { if } c \leq r .\end{cases} \\
& r_{2}=c_{1}
\end{aligned}
$$

where $Y_{1}=r_{1}, Y_{2}=\bar{Y}+\left(0.2 r_{1}\right) \epsilon$, and $\epsilon$ has a binomial $\mathbb{B}(1,7 / 8)$ distribution. If the parameters chosen are $r_{1}=1, b_{\mathrm{g}}=1.01, b_{1}=1, \lambda=.01$, and $\gamma=100$ then any $.818<\bar{Y}<1$ will satisfy $c_{1}>r_{1}$.

\section{A.7. Proof of Proposition 5}

Part (i) is a straightforward implication of Theorems 1 and 2. By the proof of Theorem 1, we know that $c_{1}(Y, 0)<r_{1}$ if $Y<2 r_{1}$ and $\alpha>0$. But Theorem 2 says that if we choose $Y_{*}$ such that $Y_{*}(1+k)=2 r_{1}$, then $c_{1}(Y, k) \geq r_{1}$ for all $Y \geq Y_{*}$, as long as $(1-k) Y \geq r_{1}$.

Proof of Part (ii): The consumer will maximize with respect to $c_{1}$

$$
\begin{aligned}
u\left(c_{1}\right) \equiv & w\left(\alpha c_{1}+(1-\alpha) r_{1}\right)+v\left(c_{1}-r_{1}\right)+0.5 v(Y(1+k) \\
& \left.-(1+\alpha) c_{1}-(1-\alpha) r_{1}\right)+0.5 v\left(Y(1-k)-(1+\alpha) c_{1}-(1-\alpha) r_{1}\right) .
\end{aligned}
$$

By $\mathrm{C}$, we know that we can choose $Y^{*}>2 r_{1}$ sufficiently close to $2 r_{1}$ such that, for all $Y \in\left(2 r_{1}, Y^{*}\right)$,

$$
(1+\alpha) v_{\mathrm{g}}^{\prime}(0) \leq v_{\mathrm{g}}^{\prime}\left(\frac{Y-2 r_{1}}{1+\alpha}\right)+\alpha w^{\prime}\left(\frac{\alpha Y+(1-\alpha) r_{1}}{1+\alpha}\right)
$$

As in the proof of Theorem 1 , this implies that $c_{1}(Y, 0)=\left(Y-(1-\alpha) \cdot r_{1}\right) /(1+\alpha)$. 
By either B1-B2 or C, we can take $k^{*}$ sufficiently small such that, for all $k \in\left[0, k^{*}\right)$,

$$
\frac{1+\alpha}{2}\left(v_{1}^{\prime}(-2 k Y)+v_{\mathrm{g}}^{\prime}(2 k Y)\right)>v_{\mathrm{g}}^{\prime}(0)+\alpha^{\prime} w\left(r_{1}\right) .
$$

Claim:

$$
c_{1}(Y, k) \leq \frac{(1-k) Y-(1-\alpha) r_{1}}{1+\alpha}<\frac{Y-(1-\alpha) r_{1}}{1+\alpha}=c_{1}(Y, 0) .
$$

\section{Proof of claim:}

Note first that, since $Y>2 r_{1}$, we have $(1+k) Y>2 r_{1}$. Therefore, $c_{1} \geq r_{1}$ by Theorem 2 provided $k \leq 1 / 2$.

(a) Suppose that $\left((1-k) Y-(1-\alpha) \cdot r_{1}\right) /(1+\alpha)<c_{1}<\left((1+k) Y-(1-\alpha) \cdot r_{1}\right) /$ $(1+\alpha)$. Then

$$
\begin{aligned}
u^{\prime}\left(c_{1}\right)= & v_{\mathrm{g}}^{\prime}\left(c_{1}-r_{1}\right)+\alpha w^{\prime}\left(r_{2}\right)-\frac{1+\alpha}{2}\left[v_{1}^{\prime}\left((1-k) Y-(1+\alpha) c_{1}-(1-\alpha) r_{1}\right)\right. \\
& \left.+v_{\mathrm{g}}^{\prime}\left((1+k) Y-(1+\alpha) c_{1}-(1-\alpha) r_{1}\right)\right]<v_{\mathrm{g}}^{\prime}(0)+\alpha w^{\prime}\left(r_{1}\right) \\
& -\frac{1+\alpha}{2}\left(v_{1}^{\prime}(-2 k Y)+v_{\mathrm{g}}^{\prime}(2 k Y)\right)<0
\end{aligned}
$$

(The second-to-last inequality follows from the fact that, for $c_{1}$ in this region, $\partial\left[v_{\mathrm{g}}^{\prime}\left(c_{1}-r_{1}\right)+\alpha w^{\prime}\left(r_{2}\right)\right] / \partial c_{1}<0,\left[(1-k) Y-(1+\alpha) c_{1}-(1-\alpha) r_{1}\right] \in(-2 k Y, 0)$ and $\left[(1+k) Y-(1+\alpha) c_{1}-(1-\alpha) r_{1}\right] \in(0,2 k Y)$.)

(b) Suppose that $c_{1}>\left((1+k) Y-(1-\alpha) r_{1}\right) /(1+\alpha)$. Then

$$
\begin{aligned}
u^{\prime}\left(c_{1}\right)= & v_{\mathrm{g}}^{\prime}\left(c_{1}-r_{1}\right)+\alpha w^{\prime}\left(r_{2}\right)-\frac{1+\alpha}{2}\left[v_{1}^{\prime}\left((1-k) Y-(1+\alpha) c_{1}-(1-\alpha) r_{1}\right)\right. \\
& \left.+v_{1}^{\prime}\left((1+k) Y-(1+\alpha) c_{1}-(1-\alpha) r_{1}\right)\right]
\end{aligned}
$$

which, by either B1-B2 or C, is negative. (a) and (b) together establish the claim, which proves Proposition 5. QED

\section{References}

Arrow, K.J., 1974. Essays in the Theory of Risk Bearing, North Holland, Amsterdam.

Benartzi, S., Thaler, R., 1995. Myopic loss aversion and the equity premium puzzle. Quarterly Journal of Economics 110, 73-92.

Boyer, M., 1983. Rational demand and expenditure patterns under habit formation. Journal of Economic Theory 31, 27-53.

Caballero, R., 1990. Consumption puzzles and precautionary savings. Journal of Monetary Economics 25, 113136.

Camerer, C., 1995. Individual decision making, In: Kagel, J., Roth, A.E. (Eds.), Handbook of Experimental Economics, Princeton University Press, Princeton, NJ, forthcoming.

Campbell, J.Y., Mankiw, N.G., 1989. Consumption, income and interest rates: Reinterpreting the time series evidence, In: NBER Macroeconomics Annual, pp. 185-250.

Campbell, J.Y., Mankiw, N.G., 1990. Permanent income, current income, and consumption. Journal of Business and Economic Statistics 8, 269-279. 
Campbell, J.Y., Mankiw, N.G., 1991. The response of consumption to income: A cross-country investigation. European Economic Review 35, 723-767.

Constantinides, G.M., 1990. Habit formation: A resolution of the equity premium puzzle. Journal of Political Economy 98, 519-543.

Duesenberry, J.S., 1952. Income, Saving and the Theory of Consumer Behavior, Harvard University Press, Cambridge, MA.

Dynan, K.E., 1993a. How prudent are consumers? Journal of Political Economy 101, 1104-1113.

Dynan, K.E., 1993b. Habit formation in consumer preferences: Evidence from panel data, Economic Activity working paper no. 143, Board of Governors of the Federal Reserve System.

Fershtman, C., 1993. On the value of incumbency: Managerial reference point and loss aversion, discussion paper no. 1020, Center for Mathematical Studies in Economics and Management Science, Northwestern University.

Georgescu-Roegen, N., 1954. Choice, expectations, and measurability. Quarterly Journal of Economics 50, 503534.

Hall, R., 1978. Stochastic implications of the life cycle-permanent income hypothesis: Theory and evidence. Journal of Political Economy 86, 971-987.

Kahneman, D., Tversky, A., 1979. Prospect theory: An analysis of decision under risk. Econometrica 47, 263291.

Kahneman, D., Knetch, J., Thaler, R., 1991. Anomalies: The endowment effect, loss aversion, and status quo bias. Journal of Economic Perspectives 5, 193-206.

Kimball, M.S., 1990a. Precautionary saving in the small and in the large. Econometrica 58, 53-73.

Kimball, M.S., 1990b. Precautionary saving and the marginal propensity to consume, NBER working paper 3403 .

Leland, H., 1968. Saving and uncertainty: The precautionary demand for saving. Quarterly Journal of Economics 82, 465-473.

Markowitz, H., 1952. The utility of wealth. Journal of Political Economy 60, 151-158.

Pagan, A., 1984. Econometric issues in the analysis of regressions with generated regressors. International Economic Review 25, 221-247.

Pratt, J., 1964. Risk aversion in the small and the large. Econometrica 22, 122-136.

Ryder, H.E., Heal, G.M., 1973. Optimal growth with intertemporally dependent preferences. Review of Economic Studies 40, 1-33.

Segal, U., Spivak, A., 1990. First order versus second order risk aversion. Journal of Economic Theory 51, 111125.

Shea, J., 1995a. Union contracts and the life-cycle/permanent-income hypothesis. American Economic Review $85,186-200$.

Shea, J., 1995b. Myopia, liquidity constraints, and aggregate consumption: A simple test. Journal of Money, Credit and Banking 27, 798-805.

Shefrin, H., Statman, M., 1985. The disposition to sell winners too early and ride losers too long. Journal of Finance 40, 777-790.

Sundaresan, S.M., 1989. Intertemporally dependent preferences and the volatility of consumption and wealth. The Review of Financial Studies 2, 73-89.

Tversky, A., Kahneman, D., 1991. Loss aversion in riskless choice: A reference-dependent model. Quarterly Journal of Economics 106, 1039-1061.

Tversky, A., Kahneman, D., 1992. Advances in prospect theory: Cumulative representation of uncertainty. Journal of Risk and Uncertainty 5, 297-323.

Zeldes, S., 1989. Optimal consumption with stochastic income. Quarterly Journal of Economics 104, $275-298$. 